\title{
$O$ aprendizado na prática e as práticas de aprendizado: A formação inicial dos magistrados da Justiça do Trabalho
}

\author{
Learning by Doing and the Practices of Learning: \\ The Initial Training of Judges on Labour Justice
}

Pedro Heitor Barros Geraldo ${ }^{1}$

Lucia Lambert de Passos Ramos ${ }^{2}$

\section{RESUMO}

Este artigo coteja duas experiências de pesquisa acerca da socialização profissional de Juízes em contextos institucionais distintos, o brasileiro e o francês. A comparação auxilia na compreensão das formas de aprendizado do trabalho prático nesses dois contextos de trabalho. A descrição dos contextos de socialização permite compreender os diferentes significados que podem ser dados ao aprendizado das práticas profissionais entre os magistrados. A comparação sugere que aprender no trabalho envolve aprender com as consequências dos erros praticados, diferentemente da prática do aprender na prática. Nesse contexto, o erro é publicamente performado e coletivamente escrutinado pelos colegas não produzindo consequências negativas para o profissional e para sua reputação no Tribunal.

\section{PALAVRAS-CHAVE:}

Formação profissional; trabalho judicial; Justiça do Trabalho; análise comparativa.

\begin{abstract}
This article collates two research experiences about the professional socialization of Judges in different institutional contexts, the Brazilian and the French. The comparison allows to understand the ways of learning practical work in these two work contexts. The description of socialization contexts allows us to grasp the different meanings of learning professional practices among magistrates. The comparison suggests that learning at work involves learning from the consequences of mistakes made, unlike the practice of learning by doing. In this context, the error is publicly performed and collectively scrutinized by colleagues and teachers, without producing negative consequences for the professional and for his reputation in the Court.
\end{abstract}

\footnotetext{
${ }^{1}$ Professor do Instituto de Estudos Comparados em Administração de Conflitos-UFF; Pesquisador bolsista JCNE da FAPERJ e Bolsista Pq 2 do CNPq; Professor permanente do Programa de Pós-graduação em Justiça e Segurança e do Programa de Pós-graduação em Sociologia e Direito.

2 Advogada; Pesquisadora do Instituto de Estudos Comparados em Administração Institucional de Conflitos (InEAC); Mestre e doutoranda no Programa de Pós-graduação em Sociologia e Direito da Universidade Federal Fluminense.
} 


\section{KEYWORDS:}

Professional Training; Judicial Work; Labour Justice; Comparative Analysis.

\section{INTRODUÇÃO}

Este artigo coteja duas experiências de pesquisa acerca da socialização profissional de Juízes em contextos institucionais distintos, o brasileiro e o francês. A comparação auxilia na compreensão das formas de aprendizado do trabalho prático nesses dois âmbitos. A descrição dos contextos de socialização permite compreender os diferentes significados que podem ser dados ao aprendizado das práticas profissionais entre os magistrados.

Descreveremos a pesquisa de dissertação de Lucia Lambert sobre a forma de socialização profissional dos Juízes do trabalho "recém-empossados" no Tribunal Regional do Trabalho do Rio de Janeiro, a partir da participação observante do curso de Formação Inicial (CFI) da Escola Judicial 1 (EJ1). Ao passo que, no contexto francês, apresentaremos a experiência de Pedro Heitor Barros Geraldo em sua pesquisa de doutoramento sobre a socialização profissional dos Juízes de proximidade na França (GERALDO, 2011a).

O processo de transformação da magistratura brasileira nos últimos anos, sobretudo a partir da Emenda Constitucional 45/04, permitiu que aflorassem no país inúmeras Escolas Judiciais. São elas órgãos de ensino criados no âmbito administrativo dos Tribunais, para dar conta da formação do seu efetivo de Juízes. Nada obstante, são escassas as pesquisas sobre o processo de socialização profissional dos Juízes no Brasil, sobretudo no âmbito dessas Escolas, não sendo possível assim avaliar a consistência e os resultados dessas iniciativas. A iniciativa de abertura da EJ1 para a pesquisa acadêmica deve ser saudada, portanto, pois contribui para dar transparência aos saberes profissionais.

A Escola Judicial do TRT da $1^{\text {a }}$ região oferece, a oito edições, ao grupo dos novos Juízes do Trabalho ingressantes na insituição, o Curso de Formação Inicial, que se constitui numa etapa inicial obrigatória de inserção do magistrado na jurisdição, denominada "formação concentrada”. O Juiz permanece ligado à Escola Judicial após o CFI, devendo participar de 
atividades e apresentarrelatórios, pelo período em média de dois anos, que precede o seu vitaliciamento. Essa é a chamada etapa de "formação continuada".

O curso de formação inicial possibilita aos novos Juízes socializarem-se com a profissão e com os saberes práticos que definem a identidade do magistrado trabalhista. A Escola é responsávelpelo início da socialização profissional do Juiz Substituto, promovendo o encontro deste com os demais magistrados e profissionais que fazem parte da realidade deste Tribunal. Nesse sentido, ela tem a capacidade de promover uma renovação constante no Tribunal, pois se apresenta como um espaço propício para o diálogo e troca de conhecimentos entre esses diversos profissionais.

\section{APRENDER NA PRÁTICA}

O aprendizado na prática é visto como uma forma indispensável para a socialização profissional no campo jurídico no Brasil. É dessa forma que se supera o abismo existente entre a teoria, aprendida na Faculdade de Direito, e a prática jurídica, presente nos diferentes contextos profissionais jurídicos. Esse aprendizado permite aos novatos socializar-se com o conteúdo do trabalho, mas também a apreenderem as identidades profissionais que vão se constituir a partir do seu envolvimento profissional.

Pouco tem se estudado sobre o modo de socialização profissional dos juristas e, especialmente, dos juízes, com exceção da pesquisa sobre a magistratura trabalhista no Brasil (FRAGALE FILHO, 2008). As sociologias norte-americana e francesa se debruçaram sobre essa questão enfatizando as formas práticas de uso da linguagem jurídica (BURNS, 1998; MERTZ, 2007) e a passagem do aprendizado prático para o aprendizado organizado por meio de uma Escola (BOIGEOL, 2010; PETIT, 2003). Esse processo de socialização profissional é bastante descrito entre outras profissões, como a medicina (BECKER et al., 1976) e a advocacia (KARPIK, 1995).

O processo de socialização permite compreender as formas de envolvimento com $\mathrm{o}$ exercício prático da profissão. O envolvimento moral com o resultado do trabalho é um objeto da sociologia das profissões do direito. Como explicam Sarat e Scheingold (1998): 
Em muitas nações a profissão normalmente se representa como servindo igual e concorrentemente o interesse público e os interesses individuais dos clients sem reconhecer adequadamente a tensão entre estas duas concepções de responsabilidade professional. Assim, operadores do direito são encorajados pela profissão organizada para realizar uma variedade de atividades pro bono e apoiar programas de assistência jurídica e serviços jurídicos. Mas este trabalho é visto como subordinado à atividade central da profissões jurídicas, que é prover um serviço jurídico remunerado por clientes particulares e institucionais. Além disto, os esforços dos serviços públicos convencionais desta natureza tem sido em grande parte restritos a responder necessidades legais não satisfeitas e aliar a profissão ao ativismo cívico consensual. (SARAT; SCHEINGOLD, 1998, p. 4) ${ }^{3}$.

Luisa Zappulli (2009) descreveu esse processo acompanhando os magistrados italianos. Isso a permitiu conhecer como os magistrados italianos organizavam suas atividades através de um aprendizado prático enquanto aprendiam as atividades cotidianas de trabalho. Ele descreveu o funcionamento do processo seletivo, o processo de nomeação até o processo de socialização atravésdo "learning by doing".

Outra dimensão dessa abordagem sobre a produção de identidades relativas às práticas profissionais é tratada por Cátia Aida Silva (2001) ao distinguir as identidades profissionais dos promotores de justiça em São Paulo. Ela demonstra nessa pesquisa como se constituem dois tiposde identidade, os promotores de gabinete e os promotores de fato, para designar o envolvimento desses profissionais com as demandas apresentadas.

$\mathrm{Na}$ França, os juízes de proximidade passaram por uma experiência do processo de socialização distinto dos juízes profissionais. Isso permitiu compreender como a justiça é realizada tendo em vista o processo de socialização desses juízes (GERALDO, 2011a). No processo de descrição, a compreensão e análise como o aprendizado prático em meio aos desafios cotidianos marcaram profundamente a forma pela qual esses juízes de proximidade prestam a justiça.

A observação participante das atividades do CFI no âmbito da Escola Judicial 1 por Lucia Lambert e Pedro Heitor, incluindo aulas, visitas e "prática tutelada", resulta em uma

\footnotetext{
${ }^{3}$ No original, "In many nations the profession regularly represents itself as serving equally and concurrently the public interest and the interests of individual clients without adequately acknowledging the tension between these two conceptions of professional responsibility. Thus lawyers are encouraged by the organized profession to undertake a variety of pro bono activities and to support legal aid and legal services programs. But this work is seen as ancillary to the central activity of the legal profession, which is to provide fee-for-service lawyering to individual and institutional clients. Moreover, conventional public service efforts of this sort have been for the most part confined to responding to unmet legal needs and to allying the profession with consensual civic activism."
} 
descrição do curso construída por meio dos significados atribuídos às suas atividades pelos novos magistrados. Oobjetivo desta experiência de observação-participante foi o de identificar, descrever e analisar como os juízes aprendem as novas atividades, categorizando os conteúdos do que foi aprendido e atribuindo um sentido formativo para sua socialização profissional enquanto juiz trabalhista. Além de compreender como os novos magistrados aprendem a se orientar por meio dos constrangimentos institucionais que vão sendo descobertos por eles ao longo deste período, sobretudo através das suasexperiências individuais.

O desenvolvimento das habilidades práticas do novo Juiz do Trabalho é submetido a uma experiência individual e idiossincrática, uma vez que o saber "teórico" transmitido em grande parte das aulas é compreendido como de natureza distinta daquele "saber prático" do exercício profissional, captado na "prática tutelada". Os erros profissionais dos novos Juízes Substitutos são considerados em uma perspectiva de culpa pessoal, uma vez que o aprendizado da sua função acontece em um momento no qual eles já se encontram credenciados para responder pela instituição, isto é, para serem responsabilizados pelos seus erros.

Esta pesquisa demonstra como o trabalho cotidiano nos tribunais é orientado por um aprendizado prático, e não mais pelo saber de matiz dogmático próprio do Direito. A abordagem etnográfica adotada se revela importante para a compreensão de como os magistrados iniciantes concebem sua nova profissão e como eles se orientam diante dos novos desafios práticos que a profissão lhes apresenta.

\section{O CURSO DE FORMAÇÃO DOS JUÍZES DO TRABALHO}

Desde o início do primeiro CFI acompanhado, notamos que os novos magistrados realizam uma distinção entre as "aulas práticas" e as "aulas teóricas". A partir dessa classificação, passamos a compreender a "prática" e a "teoria" como formas de categorização nativas. São próprias dos membros desse contexto de socialização profissional para demonstrar como os novos magistrados articulam o que é conhecimento prático e o que é conhecimento teórico. Na medida em que os temas das "aulas teóricas" não se relacionam com as atividades práticas dos Juízes, sobretudo com a sua função principal de presidir audiências, são classificados, dentro do esquema de interpretação que eles elaboram, como conhecimentos 
meramente informativos. O que é formativo, isto é, o que de fato marca a sua formação profissional enquanto Juiz do Trabalho na instituição, são os conteúdos relacionados às "aulas teóricas".

Como explicou um novo magistrado da $7^{\mathrm{a}}$ edição do curso em uma entrevista informal, o grupo dos novos Juízes está mais ligado à prática, à técnica e ao processo, como ele aponta: "O pessoal é da turma do processo, do procedimento". Ao mesmo tempo, categoriza-se o conhecimento teórico com outro significado. Como ele afirma, "Para a maioria ali, falar de história ou sociologia é um saco!". Ele considera que a expectativa da maioria dos Juízes com o Curso de formação era a de obter ferramentas práticas para realizar as audiências trabalhistas. Nessesentido, ele afirma que os novatos queriam um curso "sobre o dia a dia e os desafios do juiz em audiência, nos relacionamentos". Segundo um outro relato, era esperado por todos eles um curso mais "prático". Nesse contexto, o comentário de um magistrado da turma: "Nós ficamos lá às vezes assistindo aula pensando que poderíamos estar lendo a CLT, não sei..."

No âmbito da avaliação final do segundo CFI, grupo focal composto pelos novos magistrados da turma e presidido conjuntamente pelo Diretor e pelo Coordenador da Escola, essa questão também foi muito aborda. Uma nova magistrada opinou que a "inserção administrativa e funcional" do Juiz deveria ser o foco desses três meses iniciais de formação destinados ao CFI, exclamando que “Afinal, a gente chega aqui sem entender nada!”. Sobre essa questão, outro magistrado avaliou que o CFI não deveria ser voltado apenas para o que chamou de "conhecimentos operacionais", ao mesmo tempo em que ponderou que "dá para enxugar as aulas teóricas". Foi um terceiro magistrado que sugeriu que o curso proporcionasse aos novos magistrados "aulas de rotina de Vara", a serem presididas por diretores das Secretarias das Varas. Como ele observou, essa experiência seria muito importante na medida em que os Juízes Substitutos tendem a ficar muito separados das questões administrativas.

$\mathrm{O}$ diretor da Escola, que presidia a avaliação, aludindo à figura de um "cabo de guerra”, faz a análise de que na medida em que eles (a Escola) "puxam” os magistrados ingressantes para refletirem sobre o papel do Juiz na sociedade de forma ampla, eles (os Juízes) demandam, em um movimento contrário, conhecimentos mais práticos. Querem saber simplesmente, como anotar uma carteira, ou como realizar uma audiência trabalhista, a título de exemplo. 
Ele afirma, nesse contexto, que a função da Escola Judicial é preparar os novos magistrados para serem Juízes, o que é bem diferente da "preparação para a jurisdição". Esta última envolve uma preparação para o trabalho cotidiano da Vara, enquanto a primeira tem a ver com o lado sensível e humano do Juiz, dimensões que envolvem o exercício da sua função social. Contudo, ele assevera que já chegou a considerar a elaboração de um Curso de Formação inicial módulo concentrado, composto apenas por oficinas e atividades práticas, deslocando as aulas teóricas para a "formação difusa", devido às reiteradas críticas realizadas pelos magistrados ingressantes.

Os novos magistrados identificam como "aulas práticas” as disciplinas de deontologia; de relacionamento interpessoal; de tecnologias aplicadas, que incluem as aulas de processo eletrônico, sistemas conveniados e Juriscalc; de inserção administrativo-funcional, como as aulas sobre a Ouvidoria e Gestão documental; também as disciplinas, com destaque para as oficinas, de gestão de pessoas, de conciliação e de mediação judicial; as disciplinas de instrução judicial como a aula sobre a prova oral ministrada pelo Policial Federal e, finalmente, as disciplinas de efetividade da execução. São, portanto, todas as aulas relacionadas diretamente àquilo que eles consideram como próximos de uma "prática da atividade judicial". Para os novos magistrados, o conhecimento prático mais formativo é aquele relacionado às práticas de realização das audiências, que é passado sobretudo pelos Juízes antigos, Substitutos e Titulares, Desembargadores e Servidores do Tribunal, que formam a maior parte dos palestrantes.

Por outro lado, as "aulas teóricas" são basicamente aquelas ministradas por acadêmicos, envolvendo temas de História, Literatura, Sociologia, Economia, Direito e outros.

Os novos magistrados realizam claramente uma distinção entre o saber da academia e o saber da prática. Essa divisão de saberes serve para distinguir os conhecimentos instrumentalizáveispara fins de realização do trabalho daquele que não orienta a realização prática do trabalho. Ao se referir ao Coordenador do curso, um magistrado explicou que: " $O$ [coordenador do curso de formação] é acadêmico, mas tem um pensamento menos abstrato, mais concatenado com a realidade". Nesse sentido, operou uma divisão entre um saber instrumental "concatenado com a realidade" e outro não-instrumental ou "abstrato" que não se relaciona com a prática do trabalho. 


\section{a) As regras práticas de formação}

O conjunto de regras práticas permite aos magistrados categorizar as situações, orientando suas ações de forma adequada segundo os contextos. Essas regras são aprendidas pelos novos magistrados, no contexto do curso de formação inicial, sobretudo através das suas experiências individuais nas "audiências tuteladas", mas também por meio dos relatos dos diversos profissionais do TRT 1 nas aulas e palestras, que compartilham suas experiências prévias no Tribunal. Além dos “causos” compartilhados, as orientações mandatórias e a não construção de consensos durante as interações, que se relaciona com a lógica do contraditório, também parecem constituir os modos pelos quais os novos magistrados aprendem as regras práticas.

A organização administrativa das Varas do Trabalho é um fator decisivo de conformação do trabalho do Juiz. Existe toda uma lógica de gestão que permeia a organização de uma jurisdição trabalhista. Estando dividida em Varas, cada uma de titularidade de um Juiz em posição maisestável na carreira que a de um Juiz substituto, a jurisdição se funda em um emaranhado de relaçõespessoais, bem como de procedimentos, práticas e modos de gestão específicos, que variam muito de uma Vara para outra, ainda quando elas se localizam fisicamente lado a lado.

A frase "o procedimento do vizinho pode ser útil para a gestão da sua Vara”, de um Juiz Titular que participou do CFI, é reveladora de como há uma particularização das regras práticas das Varas. É evidente que uma não está totalmente "desconectada" da outra, mesmo porque, em última instância, todas elas se dirigem às mesmas finalidades, cobranças e expectativas institucionais. No entanto, a forma pela qual cada uma vai organizar o contingente do seu trabalho, fica à cargo dos profissionais que a compõem.

Entre esses profissionais está não apenas o Juiz, mas sobretudo os técnicos e analistas administrativos, secretários e diretores de Vara. Aliás, não raro é que os servidores continuem os mesmos por um longo período, enquanto o magistrado sofre um câmbio bem mais frequente. A consequência disso para a Vara é notável: apesar de o Juiz ser a figura de maior poder e hierarquia, é para ele indispensável a colaboração dos servidores para realização do trabalho. 
E como a estrutura administrativa das Varas é percebida pelos novos magistrados? Em um dia da programação do curso dedicado à audiência tutelada, escolhi uma nova magistrada da turma para acompanhar.

A nova juíza em questão estava acompanhada pela Juíza Titular da Vara, que estava sentada ao seu lado. Muitos magistrados da turma revelaram, em conversas informais, que preferem quando o Juiz titular não acompanha a audiência de perto, o que acontece em muitos casos quando previamente acordado entre eles. Elaboram que, quando acompanhados é como se perdessem a confiança e segurança necessária para presidir a audiência, pois sentem que de alguma maneira são desacreditados pelos advogados e partes, que não raro se dirigem ao próprio Titular, mesmo quandoé o Substituto que está no comando. Isso demonstra como a presença de um outro Juiz se torna um constrangimento na hora de tomar a decisão, que é uma atividade normalmente exercida de forma "solitária".

A presença do Juiz Titular da Vara na audiência representa, assim, mais um constrangimentopara a nova magistrada, reforçando a ideia de que existe naquela Vara um “modo de fazer" específico, procedimentos e entendimentos tipicamente adotados, todos definidos, em última instância, pela Juíza sentada ao seu lado. Ainda que o coordenador da atividade tutelada tenha afirmado, no âmbito da Avaliação Final, que foi dada "ordem clara para os Juizes Tutores não interferirem na audiência de vocês. Jamais!", existe claramente aí uma tensão.

É evidente que o Juiz Substituto não será forçado a decidir de acordo com os parâmetros do Juiz Titular, tendo autonomia e ampla liberdade de "não-conformação". Uma nova magistrada me revelou, após a "prática tutelada", que tomou pelo menos umas cinco decisões interlocutórias que iam de encontro ao que a Juíza Titular costumava decidir, o que gerou um certo desconforto, como avaliou, pois notou que "não agradou muito". Ela revelou também que não pede e nem usa os modelos de sentença da Vara, "para não ser influenciada”.

No entanto, uma situação específica em uma audiência por ela realizada evidenciou o constrangimento causado pela presença da Juíza Titular. Diante dos pedidos reiterados de uma advogada para o deferimento da oitiva de uma testemunha, não previamente arrolada no rol de testemunhas requerido pelo juízo (apesar desta não ser uma exigência na CLT), a nova magistrada hesitou, pedindo para analisar o documento da intimação que fora feita pelo Correio. A Juíza Titular, nesse momento, fez alguma consideração em baixo tom de voz, no que a 
"novata" devolveu o documento para a advogada e decidiu, finalmente, por indeferir a testemunha. No dia seguinte à audiência, indaguei a essa magistrada o motivo do indeferimento, fazendo alusão ao caso. Ela imediatamente se recordou e explicou: "Ah, você viu isso? Eu queria deferir a testemunha,mesmo porque esta não é uma exigência da CLT e eu não concordo com esse procedimento, mas a Juíza Titular virou para mim no momento em que peguei o documento e ressaltou 'Eu indefiro nesses casos!', não me deixando com muita escolha". Ela disse que não queria enfrentá-la eponderou que a citação havia sido feita apenas no dia anterior da audiência.

Foi também em uma audiência realizada por outra nova magistrada da turma que foi possível presenciar um caso parecido. O advogado de uma das partes pediu para a Juíza Substituta uma extensão de prazo para a juntada de documentos ao processo. O pedido era "super razoável”, já que a próxima audiência do processo estava marcada apenas muito para a frente e se levada em consideração a proximidade do feriado do Carnaval, como observou a nova Juíza quando por mim questionada sobre o caso, em um momento posterior à audiência. Ocorre que, e eu presenciei esse momento da audiência, a Juíza Titular que estava ao seu lado interferiu, falando em tom impaciente "Está atrasando a pauta!”, o que fez com que a nova magistrada acabasse indeferindo o pedido e pondo fim à audiência.

Vale notar que em um processo imediatamente depois, diante de mais um pedido de extensão de prazo, a nova Juíza decidiu pela manutenção do prazo original, explicando para o advogado que havia acabado de indeferir uma extensão de prazo no outro processo e queria “manter uma coerência”. A Juíza Titular elogia a sua atuação ao fim da sua performance.

Esta mesma magistrada, fez um relato muito interessante no âmbito de uma aula expositiva do curso, compartilhando com os colegas uma experiência de realização de audiências em que as sessões estavam demorando muito, na média, o que havia contribuído para o atraso considerável da sua pauta. Foi então que ela começou, conforme o seu relato, a “indeferir testemunhas". Uma colega também revela para a turma, nesse momento, o seu “medo" em atrasar a pauta do Titular. Isso representa, sem dúvidas, um constrangimento para o Juiz "tutorado". Aqui, vemos também umexemplo explícito de como as contingências do trabalho prático do dia-a-dia do Juiz constituem muitas vezes fatores determinantes das decisões interlocutórias que são exaradas pelo Juiz do Trabalho em audiência. 
No intervalo do dia do curso de visita à uma Garagem de Ônibus na Zona Oeste do Rio de Janeiro, cuja manhã de atividades se iniciou às 4:30, um dos novos magistrados relatou sua experiência em uma audiência tutelada. Ele disse que teve uma "crise existencial" quando se deparou com uma situação em que pensou: "Vou ter que divergir!”. Explicou que se surpreendeu que a Juíza Titular da Vara aceitasse um acordo de menor salário fora da negociaçãodo acordo coletivo, que significava uma perda significativa de dinheiro para o trabalhador. Ele disseque no momento em que pensou: "Nossa, ela não vai dar a diferença?", foi imediatamente procurar um meio de construir processualmente a sua decisão, de forma a divergir da Juíza Titular econceder a diferença em questão ao jurisdicionado. Esse novo magistrado ponderou que se fosse outra questão, como uma prescrição intercorrente, ele até faria o seu entendimento sucumbir. No entanto, como ressaltou, esse era um caso de sentença com o qual realmente não concordava, que feria o seu entendimento pessoal.

Nesse caso, fica demonstrado um exemplo de como a liberdade intelectual, característica da atividade do Juiz, dota-o de flexibilidade para se ajustar às estruturas do Tribunal, que se apresentam na prática como constrangimentos à sua atuação. $O$ constrangimento para esse Juiz, conforme demonstrado, foi a exigência de um esforço maior para divergir, na medida em que demandou dele a construção (sobretudo processual) dessa divergência, bem como toda uma "preparação psicológica” para fazê-lo.

Outra situação relatada pelo novo magistrado em questão foi um caso em que, sozinho na audiência. pois assim preferiu ao mesmo tempo em que tutora permitiu, ele se deparou com um pedido de procedimento relativo à expedição de guias GRU, com o qual não concordava. Ele disse que explicou para a parte que não costumava fazer o procedimento daquela forma mas que iria, ainda assim, perguntar o posicionamento do Juiz Titular acerca da questão, pois no caso dele concordar com o deferimento, ele o faria mesmo não concordando, "para não tumultuar a Vara e não causar transtorno”. Por ser um caso relativo a procedimento, ele ponderou que é o tipo de situação em que não veria problema em sucumbir o seu entendimento pessoal, em prol das questões estruturais da jurisdição.

Os novos magistrados também aprendem rapidamente que existem muitas cobranças institucionais relacionadas aos prazos para julgamento dos processos, metas a serem cumpridas e a exigência de maior celeridade na realização do trabalho. Essas cobranças suscitam, de uma forma geral, a necessidade do controle do tempo e da gestão processual. 
As instituições, como o próprio TRT, o Tribunal Superior do Trabalho (TST) e o Conselho Nacional de Justiça (CNJ) conformam, à sua maneira, a atividade judicante dos Juízes de primeiro grau, na medida em que fixam paradigmas para a sua atuação. Elas se apresentam como constrangimentos pois demandam que o Juiz, dentre outras coisas, preste bastante atenção à fundamentação das suas decisões, sendo muito importante também a orientação de reduzir à termo tudo o que acontece na audiência, inclusive protestos de advogados insatisfeitos ou eventuais indeferimentos de testemunhas ou de perguntas de advogados na instrução, de forma a evitar a anulação da sua sentença na instância superior.

Segundo o relato de uma nova magistrada, no contexto de uma oficina do curso, as súmulas e orientações jurisprudenciais "fecham situações que têm vários braços". Dessa forma, muitas vezes "jogando de for a da realidade", conforme o seu argumento, o TST acaba engessando o Judiciário e, mais especificamente, a atividade dos juízes de $1^{\circ}$ grau.

Os constrangimentos do TST são produzidos pela Jurisprudência, por exemplo por meio das orientações jurisprudenciais, responsáveis por "engessar" a atividade do Juiz de primeiro grau, que vê a sua atividade decisória limitada. Um Juiz Titular do Tribunal que deu uma aula nessa edição, disse aos novos magistrados que sempre utiliza as súmulas do TST, "Mesmo que ache tosca, porque depois sobe e eles mudam". Nesse momento, ele se refere ao Tribunal como "os velhinhos lá de cima”.

Um Juiz veterano do Tribunal que assistia à disciplina de instrução oral junto à turma dos novos magistrados, compartilhou com os novos colegas que sentia que tinha que ouvir todas as testemunhas no âmbito das audiências que presidia, "mesmo de saco cheio", já que o Tribunal tendia a anular as sentenças dos Juízes de $1^{\circ}$ grau com relativa facilidade.

Sobre a instituição do CNJ e, mais especificamente, a questão da Conciliação que ela coloca para a Justiça do Trabalho, onde é cada vez mais reforçada a importância de se fomentar o acordona fase inicial do processo, muito é falado no CFI.

A conciliação se tornou uma realidade na dinâmica da Justiça do Trabalho e no TRTRJ issose verifica com extrema facilidade, seja na perspectiva de "emponderar o indivíduo", como é justificado por muitos magistrados, seja ela utilizada com a estreita finalidade de diminuir o númerode processos da Vara, como se visualiza com clareza. Um novo magistrado, após o curso e já inserido plenamente inserido na jurisdição, diz que hoje considera a 
conciliação uma "estratégia de sobrevivência". Afinal, ela facilita a gestão dos processos, diminuindo o contingente de trabalho.

Como explica uma nova magistrada no âmbito de uma das aulas do curso, o acordo é fomentado no TRT 1 tanto por uma questão de determinação legal, pois a lei trabalhista prevê duas tentativas de acordo no âmbito do processo - uma no início e outra ao final, bem como pela realidade da quantidade de processos. Nesse contexto, participar ativamente da conciliação e homologar acordos se revela uma "estratégia de sobrevivência", pois "A pauta é tão grande quese a gente não fizer alguns acordos, não dá conta”, como disse um juiz novato.

Em todas as audiências tuteladas que eu assisti os novos Juízes foram, à sua maneira, incisivos na fase da conciliação. Um novo magistrado iniciou uma audiência dessa forma: "Hoje tem acordo, não é Doutores?" Outra magistrada ressaltou no momento preliminar da audiência: "Vamos tentar a fazer o acordo e depois, se não der certo, a gente faz a instrução, sem problemas."e se pôs a fazer cálculos com base no salário do reclamante, adotando uma postura bem ativa. Não raro são os casos em que o Juiz se vale da ineficiência da própria instituição para estimular o acordo, por exemplo alertando para os riscos da demora do processo e das deficiências da tutela judicial.

Mas foi um outro caso que saltou aos olhos: a nova magistrada levou ao extremo, na audiência tutelada, a iniciativa da conciliação e interveio: "Há alguma proposta de acordo Doutores? Para fechar o processo...", seguido de outra intervenção: “a proposta dele está bem razoável, Doutor”, fazendo menção aos efeitos reflexos. Logo em seguida, começou a barganhar com os advogados, "Pode ser em duas vezes, Doutor!", seguido de intervenções como: "Liga para a empresa!" e "se for julgado procedente esse valor aumenta, hein!". Finalizou assim: "Ossenhores querem inverter a pauta para dar uma ligadinha??! Ok”. Quando as partes saíram dasala, ela deu boas gargalhadas com a Juíza Titular, que sentada ao seu lado pareceu ter gostado bastante da sua performance.

Já em uma Comarca na Zona Oeste do RJ, o Juiz Substituto organiza a pauta reservando um dia do curso para a audiência tutelada, ele aprendeu que lá a organização da pauta de audiências é feita de uma forma diferente. A Juíza Titular daquela Vara reservava um espaço muito curto de intervalo entre as audiências, o que inicialmente saltou aos olhos do novo magistrado, que se perguntou se aquilo não geraria fatalmente um atraso da pauta. No entanto, o procedimento é o seguinte como ela explicou para ele no carro: reserva-se pouco tempo para 
cada processo porque este é todo destinado à tentativa de conciliação. Não havendo acordo, o processo é automaticamente remetido para o final da pauta, o que funciona como um elemento que, para dizero mínimo, coloca uma vantagem a mais na conciliação. A Juíza Titular observa que, adotando esse procedimento, acaba dando uma oportunidade para que os advogados e as partes conversem entresi, ao longo da espera, facilitando que entrem em um acordo.

\section{AS PRÁTICAS DE APRENDIZADO}

De modo comparativo, os modelos de "learning by doing” próprios de instituições que orientam os novatos para o trabalho por meio de estágios profissionais e de uma qualificação progressiva com as responsabilidades para o desenvolvimento do trabalho. Por contraste, a experiência na justiça francesa (GERALDO, 2011a) demonstra o quanto são distintas as formas de socialização para o trabalho profissional no âmbito dos fóruns. Na França, há uma responsabilidade institucional que orienta o aprendizado. Os “auditeurs de justice” não são responsabilizados profissionalmente por seus erros. O erro na profissão é visto como uma parte do aprendizado (HUGHES, 1951), que é realizado mediante supervisão numa perspectiva de responsabilidadeinstitucional, não como uma falta pessoal.

A comparação entre as experiências busca ressaltar as diferenças e especificidades contextuais e locais que podem ser consideradas como uma produção socialmente compartilhada pelos membros da sociedade. A comparação por contraste permite, assim, melhor compreender os significados do que fazemos para nós mesmos enquanto membros da sociedade. Roberto Kant de Lima (KANT DE LIMA, 2009) explica a comparação como uma forma que nos permite estranhar a nós mesmos. Os significados podem ser compreendidos com e pelo contraste. Isto faz deste significado o resultado de uma comparação contextualmente referenciada, que se apresenta apenas como possibilidade para a construção de mais hipóteses, mas que não pode ser nunca utilizadacomo uma régua valorativa entre os significados que são comparados (GERALDO; BARÇANTE, 2014). Não há nenhuma pretensão universalista no exercício de comparar esses contextos, mas sim de explicitar os seus significados por meio do "vis-à-vis". 
Buscamos entender como o "aprender na prática” é compreendido pelos juízes franceses como um sentido pedagógico positivo em relação ao erro; ao passo que, comparativamente, no Brasil podemos descrevê-lo como um "aprender durante a prática" profissional, assumindo o profissional as consequências positivas e negativas do erro. Por essa razão, a discussão sobre o significado do erro profissional em ambos os contextos de socialização é tão importante. A avaliação sobre os erros permite ao mesmo tempo identificar que, em ambos os contextos, eles se caracterizam como um saber profissional relevante para o seu exercício.

No contexto francês, o erro é uma parte importante do "aprender na prática". Ele não produzconsequências negativas para a reputação profissional no âmbito de suas relações profissionais. Isto é, o erro é tolerável e serve unicamente ao aprendizado daquele "saber" considerado pelos membrosde um grupo ocupacional como "profissional". Nesse contexto, o auditeur de justice não é um juiz no exercício de suas funções. É um novato. É importante que ele se socialize com as práticas e os limites de sua profissão na École Nationale de la Magistrature, permanecendo nessa condição por

30 meses. O erro faz parte de um aprendizado não apenas individual, mas que também é publicamente performado e coletivamente escrutinado pelos colegas e professores. Os colegasaprendem com o erro dou outro, os professores se socializam com as dificuldades e limites dos novatos - o que permite aprender a como antecipar as dificuldades e dúvidas dos futuros novatos. - e, portanto, a instituição incrementa seu savoir-faire institucionalizado em suas práticas cotidianas sobre como treinar novos juízes.

Em sua pesquisa, Geraldo (2011a) se apresentou para um stage num pequeno fórum francês.No curso das atividades, fui convidado para redigir uma sentença sob os olhares da Greffière-en- chef, a chefe da secretaria, ele me disse para escrever o que eu julgava ser adequado. Diante do texto que tinha acabado de digitar, eu hesitei e parei de escrever. Ela insistiu para eu continuar escrevendo para que ela pudesse me corrigir, caso eu errasse. Ela disse: "Vai. Você não está arriscando nada!" Eu continuei escrevendo e ela corrigiu o texto na minha frente. Minha reação inicial - com uma socialização nas práticas jurídicas no Brasil — foi o de esperar que o meu trabalho pudesse ser interpretado negativamente. A partir dessa experiência, pude compreender uma outra forma de socialização para o trabalho. Uma forma que não conhece o erro associado à sanção negativa. 
Essa forma de aprender com o erro é bastante distinta daquela que experimentamos na socialização nas práticas jurídicas brasileiras. Nestas, desempenhamos no estágio muitas atividades delegadas tacitamente das quais não podemos falar que fazemos. Muitas vezes assumimos o ônusda atividade, garantido pela reputação profissional que está se constituindo. Essas delegações são tácitas e poucas vezes explícitas, como demonstram essas chamadas de estágio divulgadas na rede social Facebook e de forma impressa no tribunal, conforme as imagens abaixo:
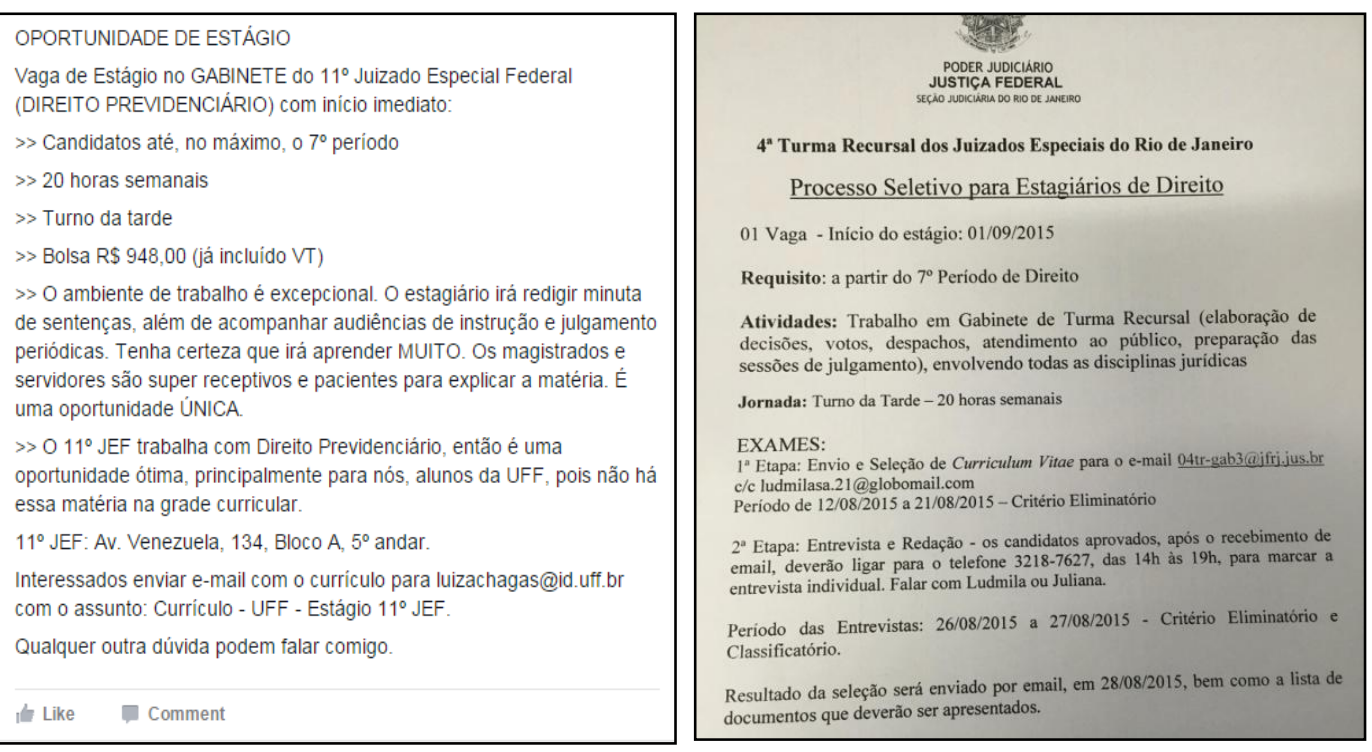

As chamadas de estágio acima demonstram explicitamente as atividades que os “estagiários"devem desempenhar uma série de atividades práticas, como a "preparação de minutas de sentenças"ou “elaboração de decisões, votos, despachos, atendimento ao público, preparação das sessões de julgamento". A chamada da esquerda é orientada para um público específico, os alunos da Faculdade de Direito da Universidade Federal Fluminense. Este anúncio ressalta "a ótima oportunidade" desse estágio para esse público em razão da ausência da disciplina na "grade curricular". Isso demonstra como o aprendizado prático é valorizado nessa cultura jurídica.

As chamadas de estágio acima demonstram explicitamente que os "estagiários" devem desempenhar uma série de atividades práticas, como a "preparação de minutas de sentenças" ou "elaboração de decisões, votos, despachos, atendimento ao público, preparação das sessões 
de julgamento". A chamada da esquerda é orientada para um público específico, os alunos da Faculdade de Direito da Universidade Federal Fluminense. Este anúncio ressalta "a ótima oportunidade" desse estágio para esse público em razão da ausência da disciplina na "grade curricular”. Isso demonstra como o aprendizado prático é valorizado na nossa cultura jurídica.

\title{
4. APRENDER NO TRABALHO E O PROBLEMA DO ERRO PROFISSIONAL
}

$\mathrm{O}$ modelo da EJ1se orienta por uma prática de aprendizado que responsabiliza o erro. $\mathrm{O}$ Juiz aprende no exercício de suas funções, assumindo as consequências de uma possível falha. Aprender no trabalho é muito distinto da prática do aprender fazendo.

Ao descrever a forma de aprendizado da polícia militar do Estado do Rio de Janeiro,Jacqueline Muniz (1999) explica: “constata-se a valorização da experiência pessoal como umaforma de "saber-ato" que é construído em um processo simultâneo de "training on the job" e troca de vivências entre policiais mais e menos experientes" (1999, p. 17). Continua assim:

\begin{abstract}
Outros qualificativos tais como o pragmatismo, a crueza, o sentimentalismo, a nostalgia, a personalização, a empiria, o detalhismo, a adaptabilidade e a presteza, são associados a esse saber "em estado de alerta". Um saber reestruturado a cada nova circunstância atendida, preparado para assistir ao "pior de nós mesmos" e disposto a conviver com os "lados desagradáveis da vida". Através das múltiplas caracterizações desse saber procura-se, então, resgatar um conhecimento singular construído nas ruas da cidade e, por meio dessa empresa, contextualizar os desafios, impasses e alternativas experimentados pelos PMs da ponta da linha em razão da complexa tarefa de preservar uma ordem pública contemporânea.’(MUNIZ, 1999, p. 17-18)
\end{abstract}

Essa experiência difícil, de aprender com as consequências de um erro, é o que caracteriza o "training on the job" em contraste com o "learning by doing". Essa forma de treinamento indica quea evitação do erro leva a estratégias como a de culpabilização do outro. Sociologicamente, essa questão é tratada nos relatos de competições profissionais, como explica Bonelli (2010) em relação às disputas intra e extra-profissionais da área jurídica. Essas competições profissionais podem criar igualmente uma relação de um aprendizado onde não se pode errar e que valoriza dissimulação do erro como um saber profissional importante. 
Os erros praticados pelos profissionais que aprendem no trabalho são tratados como transgressões individuais. A solução para essas transgressões é a eventual punição e exclusão dos profissionais. Entretanto, as próprias instituições não colocam em questão as suas práticas que ensejam uma reprodução indesejada, permanecendo a reprodução desse conhecimento prático sobre o exercício das funções profissionais intocada. Isto significa que as questões importantes para o exercício da profissão não são construídas como problemas institucionais.

Desse modo, as instituições não são capazes de produzir políticas de identificação, preservação e reprodução de um saber prático transparente para os membros externos. As eventuais punições e exclusões dos profissionais não põem em causa a reprodução desse conhecimentocorporativo, mas apenas as condutas individuais de cada profissional. Por isso, essas instituições preservam suas práticas sacrificando aqueles que não souberam reproduzir esse conhecimento de forma adequada do ponto de vista das próprias corporações.

O exercício da atividade de julgar no Brasil pressupõe o conhecimento, por parte dos juízes, de como essa atividade deve ser performada. O saber prático de julgar considera imporante o conhecimento sobre as hierarquias profissionais, como aquelas entre o Juiz Titular e o Juiz Substituto. Esse saber está também inscrito nas práticas de aprendizado da atividade de julgar.

A instituição relega as consequências do aprendizado às aptidões pessoais. A formação é, portanto, idiossincrática. Cada um experimenta o aprendizado de uma forma distinta. Os juízes não experimentam a formação profissional de forma coletiva. Os sentidos do trabalho são aprendidos a partir de um sistema de relevâncias que interpreta as experiências individuais de um ponto de vista particular. Tal qual a descrição do aprendizado particularizado das práticas profissionais dos membros do Ministério Público do Estado do Rio de Janeiro, como demonstra Barçante (2015).

A socialização profissional significa o aprendizado de diferentes atividades, seus significados e sua importância diante do trabalho. Schutz (1962) descreve essa avaliação sobre a orientação da ação como um sistema de relevâncias. Para ele, "Relevância não é naturalmente inerente enquanto tal, ela é o resultado de uma atividade seletiva e interpretativa das pessoas dentro da natureza ou observando a natureza." (SCHUTZ, 1962, p. 5) ${ }^{4}$. Schutz (1962) explica

\footnotetext{
${ }^{4}$ No original, "Relevance is not inherent in nature as such, it is the result of the selective and interpretative activity of man within nature or observing nature."
} 
que é dessa forma que o conhecimento científico se opera, selecionando dados pertinentes segundo os interesses e finalidades dos pesquisadores. Porém, esse é o mesmo método utilizado pelas pessoas para categorizar o mundo, estabelecendo hierarquias e atribuindo valores aos fatos, objetos e situações da vida cotidiana.

O profissionalismo, aqui, se apresenta apenas como mais um sistema de relevâncias segundo as contingências do trabalho cotidiano. Freidson (1996) analisa o processo de estabelecimento e manutenção das instituições do profissionalismo. Ele explica a importância sobre a reflexão do "corpo de conhecimentos e qualificações sobre o qual uma ocupação reivindica jurisdição" (FREIDSON, 1996, p. 8). Assim, o conteúdo do profissionalismo se relaciona diretamente com a identificação e descrição do trabalho cotidiano. Ele explica que:

\begin{abstract}
“Os profissionais são aquelas pessoas que criam, expõem e aplicam aos assuntos humanos o discurso de disciplinas, campos, corpos demarcados de conhecimento e qualificação. Esse é seu trabalho, que não pode ser desempenhado sem instituições que lhes garantam apoio econômico, poder e organização. Meu quadro de referência procura fornecer os recursos analíticos que tornam possível mostrar como as disciplinas, os campos ou os corpos de conhecimento e qualificação podem existir enquanto empreendimentos sociais, bem como traçar as fontes de variação em poder e autonomia que possam ter em diferentes espaços e tempos. Ao fazê-lo, ele relaciona as idéias à fundação material, sem a qual teriam pouco poder" (FREIDSON, 1996, p. 9).
\end{abstract}

A organização social da justiça no Brasil submete os profissionais a estatutos jurídicos desigualados. Nesse sentido, as regras jurídicas, que deveriam orientar a atividade dos distintos profissionais, são substituídas pelas relações hierárquicas entre as profissões jurídicas. Esse conhecimento prático, de observar as regras respeitando as regras formais do direito, faz parte deum conhecimento prático presente na Faculdade de Direito e nos estágios. Afinal, os responsáveis pelo estágio de direito são meros acolhedores e orientadores para os novatos, o que desarticula o conhecimento da Universidade e o conhecimento dos Tribunais.

Contrariamente, Bourdieu explica n'A força do Direito (1986) que o campo jurídico está estruturado a partir da divisão entre os professores e os práticos do direito. Ele aponta não apenas para uma análise, mas sobretudo para uma descrição da divisão do trabalho dos juristas franceses, onde os juízes não lecionam e os professores não julgam. Para essas instituições, a socialização profissional é uma responsabilidade das corporações, onde o esprit de corps é 
constituído pela reprodução das práticas profissionais. Desse ponto de vista, o ensino das práticas profissionais não pode ser delegado a um outro corpo profissional. Apenas em casos de mobilidade controlado pelas corporações, como ocorre na França (FONTAINHA, 2011).

No Brasil, a socialização profissional é relegada às experiências individuais de aprendizado. Por isto não se orientam — e nem podem se orientar — por protocolos, ou pelas regras jurídicas cujos sentidos são consensuais. A socialização não é um problema institucional, mas sim dos profissionais individualmente considerados. $\mathrm{O}$ conhecimento prático do exercício da uma atividade profissional orienta os seus membros a agirem de forma hierárquica em relação aos diferentes sujeitos, seja através das sanções sobre os erros, seja por meio das "carteiradas" sobre os demais membros, para dissimular os erros ou atribuir a culpa a outrem. Assim, a socialização com as práticas profissionais permite também compreender as diferentes instituições.

Veríssimo (2012) descreve a dissimulação do erro na Guarda Municipal de São Gonçalo por meio da categoria "pagar embuste". Ele explica que "trata-se de uma espécie de esperteza, que acaba se mostrando bastante eficiente diante da lógica vigente na tradição cultural brasileira, queé a da não explicitação dos conflitos sociais, uma vez que ela desarruma a ordem preestabelecida" (VERÍSSIMO, 2012, p. 159). A dissimulação do erro por meio da hierarquia ordena explicitamente as relações, sancionando aqueles que não dominam os saberes práticos do exercício de uma profissão.

Por sua vez, Geraldo (2011a) descreve as competições profissionais no contexto francês,onde a criação de um novo tipo de magistrado provocou disputas entre os juízes de proximidade eos demais juízes (de carreira), que se identificaram como "profissionais". Os conflitos entre esses grupos se apresentavam a partir de uma avaliação de um terceiro membro dos fóruns: os secretários (GERALDO, 2015). Os secretários produziram uma avaliação negativa sobre os novos membros dotribunal, sancionando os Juízes de proximidade no exercício da atividade de julgar.

O contraste com a experiência francesa permite analisar como os novos juízes de proximidade compreendem a atividade de julgar estritamente como decidir a partir da lei, tal como pode ser idealizada por alguém não socializado com os constrangimentos do exercício de uma profissão. Essa atividade requer mais do que o conhecimento das regras de direito, ela supõe a compreensão entre as diferentes consequências de se tomar uma decisão do ponto de 
vista das práticas locais de gestão da secretaria, as consequências para as partes do processo, os protocolos práticos para se dar fim ao processo, ou seja, a articulação cognitiva prática entre as regras dedireito e as formas de atribuição de sentido às normas.

Julgar, para os juízes profissionais franceses, tem a ver como encerrar o processo; identificar as formas práticas de tratar as dimensões do conflito que se apresenta; reduzir o volume de trabalho burocrático para a secretaria; aliviar o trabalho prático do secretário durante a audiência;poupar e otimizar decisões judiciais, evitando mais trabalho burocrático para os secretários, reconhecendo e sancionando - aqui entendida nos sentidos negativos e positivos - decisões do secretário sobre o conteúdo do processo ou do procedimento; evitando o adiamento desnecessário das audiências; poupando sanções ao comportamento dos presentes em audiência; sancionando menos as falas fora de hora dos participantes das audiências e informando da forma mais prática possível a consequência de suas decisões. Julgar é um exercício de considerar tudo isso ao tomar a decisão. Os secretários reconheciam como estas as dimensões para a tomada de decisão. Entretanto, os Juízes de proximidade não consideravam todas essas atividades como dimensões da produção da sua decisão.

Ora, julgar é uma atividade profissional prática. Por profissional, nos referimos ao conteúdo do trabalho prático cotidiano, que permite dizer o conteúdo dos profissionalismos (FREIDSON, 1998). Essa atividade está embebida em condições sociais que permitem escolher as relevâncias, pertinências e adequações de suas ações. Considera o que e como se pode fazer, a partir do conhecimento das hierarquias das atividades e das relações pessoais entre os membros de sua profissão. Julgar funciona assim enquanto uma prática. A orientação das decisões é o resultado de uma escolha contextual e localmente adequada. O conhecimento abstrato do silogismo jurídico não se relaciona com um conhecimento das consequências práticas no âmbito das relevâncias, pertinências e adequações socialmente produzidas entre os membros neste contexto de trabalho.

\section{CONCLUSÃO}

A observação e descrição dos cursos de formação dos magistrados da Justiça do Trabalho noRio de Janeiro demonstram a existência de orientações tácitas a respeito do que os 
novos magistrados aprendem e como aprendem, como se houvesse um currículo "oculto" para a sua formação, assim como tem se demonstrado na formação policial, em que os dilemas da formação e treinamento já são tópicos de discussão estabelecidos (KANT DE LIMA, 2000; MENDES DE MIRANDA, 2008). Esse conhecimento tácito sobre as práticas profissionais foi apresentado na pesquisa em duas partes: a categorização das aulas práticas e teóricas e as regras práticas para o exercício da função do Juiz do Trabalho. A comparação entre experiências de pesquisa, no Brasil e na França, permitiu-nos identificare descrever alguns dos esquemas de interpretação de membros institucionais ligados à magistraturae como eles organizam o mundo social no contexto de sua socialização profissional.

No caso do TRT 1, os novos magistrados categorizam o conhecimento e os saberes que circulam no curso de formação de um modo bem específico, fazendo claramente uma distinção entre o saber da academia e o saber da prática. Essa divisão de saberes serve para distinguir os conhecimentos instrumentalizáveis para fins de realização do trabalho daquele que não orienta a realização prática do trabalho (GERALDO, 2011b).

Para os novos magistrados, o conhecimento prático mais formativo é aquele relacionado às práticas de realização das audiências, que é passado pelos Juízes Titulares, Desembargadores e Servidores do Tribunal. Por sua vez, a maior parte das "aulas teóricas" não se articulam com as questões mais diretamente ligadas à prática do juiz.

O conjunto de regras práticas permite aos magistrados categorizar as situações, orientando suas ações de forma adequada segundo os contextos. Essas regras são aprendidas pelos novos magistrados, no contexto do curso de formação inicial, por meio dos relatos dos profissionais do TRT da $1^{\mathrm{a}}$ região nas palestras, que compartilham suas experiências prévias no Tribunal, sobretudo em audiência. Além dos "causos" compartilhados, as orientações mandatórias e a não construção de consensos durante as interações, que se relaciona com a lógica do contraditório, também parecem constituir os modos pelos quais os novos magistrados aprendem as regras práticas.

As formas de categorização das "aulas práticas" e "teóricas" serve para classificar o conhecimento entre os novos magistrados. Além disso, a qualidade do conhecimento não estáapenas relacionada à instrumentalização para a realização do trabalho prático, mas também com os desafios da socialização. O tornar-se magistrado está relacionado com o aprendizado das etiquetas etrejeitos de como ser um juiz. Essas regras de socialização estão diretamente 
relacionadas com um conhecimento tácito sobre a realização do trabalho que não é apresentado enquanto um tópico de discussão, mas sim como descobertas individuais.

A socialização profissional dos Juízes no Brasil não é um problema institucional, mas sim dos profissionais individualmente considerados. O Juiz do Trabalho aprende na prática, isto é, no exercício de suas funções, assumindo as consequências dos seus erros. Aprender no trabalho envolve aprender com as consequências dos erros praticados, que são tratados como transgressões individuais. Muito distinta é a prática do aprender na prática, presente na socialização dos magistrados franceses. Nesse contexto, o erro é publicamente performado e coletivamente escrutinado pelos colegas e professores, não produzindo consequências negativas para o profissional e para sua reputação no Tribunal.

\section{REFERÊNCIAS BIBLIOGRÁFICAS}

BARÇANTE, L. F. DE S. O "meu", o "seu" e o nosso. A gestão particularizada dotrabalho realizado no Ministério Público do Estado do Rio de Janeiro. Dissertação de MestradoNiterói: Universidade Federal Fluminense, 2015.

BECKER, H. S. et al. Boys in White. Reprint edition ed. New Brunswick, N.J: Transaction Publishers, 1976.

BOIGEOL, A. A formação dos Magistrados: Do aprendizado na prática à escolaprofissional. Revista ética e filosofia política, v. 2, n. 12, p. 61-97, 2010.

BONELLI, M. DA G. As interações dos profissionais do direito em uma Comarca do Estadode São Paulo. In: SADEK, M. T. (Ed.). . O sistema de justiça. Rio: Centro Edelstein, 2010. p. $24-70$

BOURDIEU, P. La force du droit. Actes de la recherche en sciences sociales, v. 64, n. 1, p. 3-19, 1986.

BURNS, S. Practicing Law: A Study of Pedagogic Interchange in a Law School Classroom. In: TRAVERS, M.; MANZO, J. F. (Eds.). . Law in Action: Ethnomethodological and Conversation Analytic Approaches to Law. Aldershot, Brookfield, Singapore et Sydney: AshgatePublishing, 1998. p. 183-208.

FONTAINHA, F. D. C. Les (en)jeux du concours: Une analyse interactionniste du recrutement à l'École Nationale de la Magistrature. Saarbrücken: Éditions Universitaires Européenes, 2011.

FRAGALE FILHO, R. DA S. Aprendendo a ser juiz: A Escola da Magistratura doEstado do Rio de Janeiro. Rio de Janeiro: Topbooks, 2008. 
FREIDSON, E. Para uma Análise Comparada das Profissões: A Institucionalização do Discurso e do Conhecimento Formais. Revista Brasileira de Ciências Sociais, v. 11, n. 31, p. 141-155, 1996.

FREIDSON, E. O renascimento do profissionalismo. São Paulo: Edusp, 1998.

GERALDO, P. H. B. La Proximité au Palais: Une analyse de la socialisation des jugesde proximité. Sarrebruck: Éditions Universitaires Européennes, 2011a.

GERALDO, P. H. B. A proximidade dos juízes: Uma análise da socialização de juízes nãoprofissionais. Revista de Ciênciais Sociais (UGF), v. 17, p. 289-319, 2011 b.

GERALDO, P. H. B. Profissionalismo e "Senso Prático": Uma Análise Praxeológica do Trabalho na Secretaria de um Fórum Francês. In: FONTAINHA, F.; GERALDO, P. H. B. (Eds.). .Sociologia Empírica do Direito. Curitiba: Juruá, 2015. p. 131-156.

GERALDO, P. H. B.; BARÇANTE, L. F. DE S. A (Des)Confiança na Polícia: Uma Comparação entre a Relação do Ministério Público e a Polícia no Brasil e na França. Anais da 38'Encontro Anual da ANPOCS, 2014.

HUGHES, E. C. Mistakes at Work. The Canadian Journal of Economics and Political Science / Revue canadienne d'Economique et de Science politique, v. 17, n. 3, p. 320-327, 1951. KANT DE LIMA, R. Carnavais, Malandros e Heróis: o dilema brasileiro do espaço público. In: GOMES, L. G.; BARBOSA, L.; DRUMMOND, J. A. (Eds.). . O Brasil não é para principiantes. Rio de Janeiro: FGV Editora, 2000. p. 105-124.

KANT DE LIMA, R. Ensaios de antropologia e de direito: acesso a justica e processos institucionais de administracao de conflitos e producao da verdade juridica em uma perspectiva comparada. Rio de Janeiro: Lumen Juris, 2009.

KARPIK, L. Les avocats: entre l'État, le public et le marché: XIIIe-XXe siècle. Paris: Gallimard, 1995.

MENDES DE MIRANDA, A. P. Dilemas da formação policial: treinamento, profissionalização e mediação. Educação Profissional: Ciência e Tecnologia, v. 3, n. 1, p. 67-76,dez. 2008.

MERTZ, E. The Language of Law School: Learning to “Think” Like a Lawyer. Oxford: Oxford University Press, 2007.

MUNIZ, J. DE O. "SER POLICIAL É, SOBRETUDO, UMA RAZÃO DE SER": Cultura e Cotidiano da Polícia Militar do Estado do Rio de Janeiro. Rio de Janeiro, 1999.Disponível em: $\quad<$ http://www.ucamcesec.com.br/wordpress/wpcontent/uploads/2011/05/Ser_policial_sobretudo_razao_ser.pdf >. Acesso em: 14 nov. 2015.

PETIT, J.-G. (ED.). Une justice de proximité la justice de paix,1790-1958. Paris: Presses universitaires de France, 2003.

SARAT, P. A.; SCHEINGOLD, A. S. S. A. Cause Lawyering: Polítical Commitmentsand Professional Responsibilities. Oxford: Oxford University Press, 1998. 
SCHUTZ, A. Collected Papers: The Problem of Social Reality. The Hague: Martinius Nijhoff, 1962. v. I

SILVA, C. A. Justiça em jogo: novas facetas da atuação dos promotores de justiça. São Paulo: EdUSP, 2001.

VERÍSSIMO, M. A estratégia do embuste: A Guarda Municipal do Rio de Janeiro e as políticas públicas de segurança. Revista Ética e Filosofia Política, v. 1, n. 15, p. 150-168, 2012.

ZAPPULLI, L. Magistrati si diventa: Etnografia della formazione professionale. Milano: Franco Angeli, 2009. 